\title{
Effects of Pulsed-Electrodeposition Parameters on the Property of Aluminum Film onto Sintered NdFeB Magnets
}

\author{
Fang Xu ${ }^{1}$, Li Jiang ${ }^{1,2, *}$, Jianhu $W u^{1}$, Xiting Shen ${ }^{1}$, Qiyun Huang ${ }^{1}$, Yundan Yu ${ }^{1}$, Chunan Cao ${ }^{2}$, Guoying \\ Wei ${ }^{l}$, Hongliang $G e^{l}$ \\ ${ }^{1}$ College of Materials Science and Engineering, China Jiliang University, Hangzhou, China; \\ ${ }^{2}$ Department of Chemistry, Zhejiang University, Hangzhou 310027, China \\ *E-mail: jiangliwhu@126.com
}

doi: $10.20964 / 2017.01 .46$

Received: 17 October 2016 / Accepted: 22 November 2016 / Published: 12 December 2016

\begin{abstract}
The aim of this study is to investigate the pulse-electrodeposition parameters on the property of aluminum (Al) film onto sintered neodymium-iron-boron $(\mathrm{NdFeB})$ magnets at room temperature from acidic AlCl-1-ethyl-3-methylim-idazolium chloride ( $\mathrm{AlCl}_{3}$-EMIC) ionic liquid (2:1 molar ratio $\mathrm{AlCl}_{3}$ EMIC). The effects of pulse frequency and duty ratio on the surface morphology, particle size, thickness, hardness, deposition rate, preferred orientation of Al grains and corrosion resistance of the Al films were researched. The results show that the increase of duty ratio can promote the deposition rate, particle size and relative surface roughness of $\mathrm{Al}$ films; while the increase of pulse frequency can accelerate the deposition rate of $\mathrm{Al}$ film and reduce its particle size and relative surface roughness. The optimum Al film with a smooth surface and good corrosion performance were obtained at the condition of $i_{p}=12.5 \mathrm{~mA} / \mathrm{cm}^{2}, r=0.5, f=5 \mathrm{~Hz}$.
\end{abstract}

Keywords: NdFeB magnets; Pulse-electrodeposition; Aluminum; Ionic liquid

\section{FULL TEXT}

(C) 2017 The Authors. Published by ESG (www.electrochemsci.org). This article is an open access article distributed under the terms and conditions of the Creative Commons Attribution license (http://creativecommons.org/licenses/by/4.0/). 